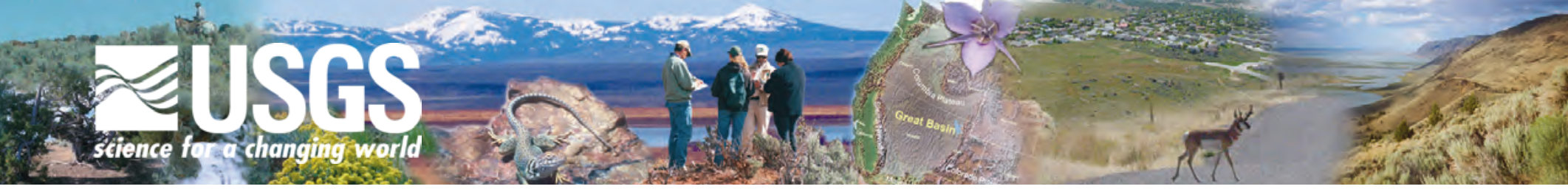

\title{
Science for the Changing Great Basin
}

\section{T}

he U.S. Geological Survey

(USGS), with its multidisciplinary

structure and role as a federal science organization, is well suited to provide integrated science in the Great Basin of the western United States. A research strategy developed by the USGS and collaborating partners addresses critical management issues in the basin, including invasive species, status and trends of wildlife populations and communities, wildfire, global climate change, and riparian and wetland habitats. Information obtained through implementation of this strategy will be important for decision-making by natural-resource managers.

The Great Basin is an expanse of over 2.6 million square kilometers (1 million square miles) of semi-arid lands punctuated by numerous mountain ranges in the western United States (Figure 1). Because of the large amount and contiguity of public lands in the basin, the region offers a compelling opportunity to conduct landscape-level, applied science in a relatively understudied region.

In the Great Basin, public land uses are diverse and ever-increasing: water development, road networks, mining, grazing

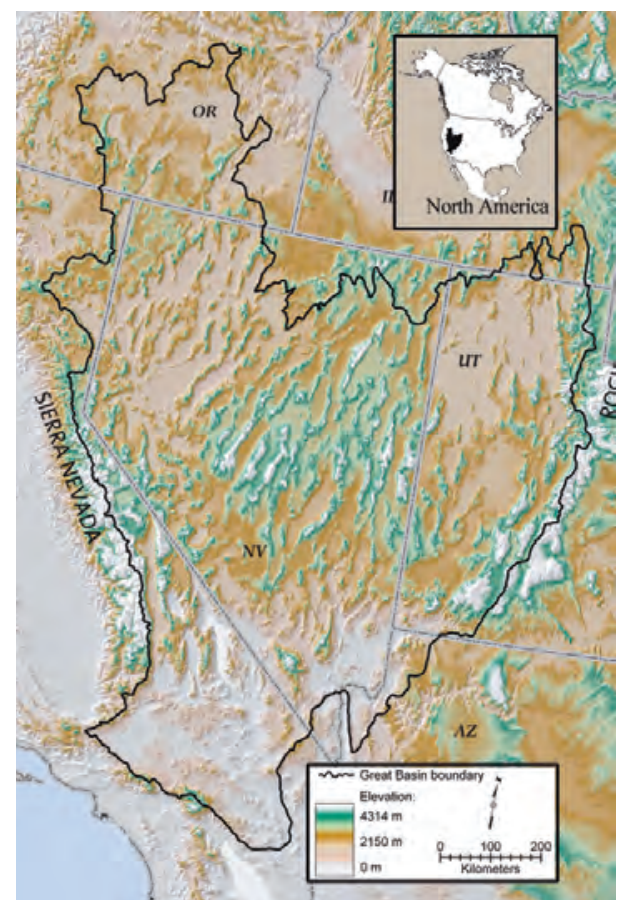

U.S. Department of the Interior U.S. Geological Survey

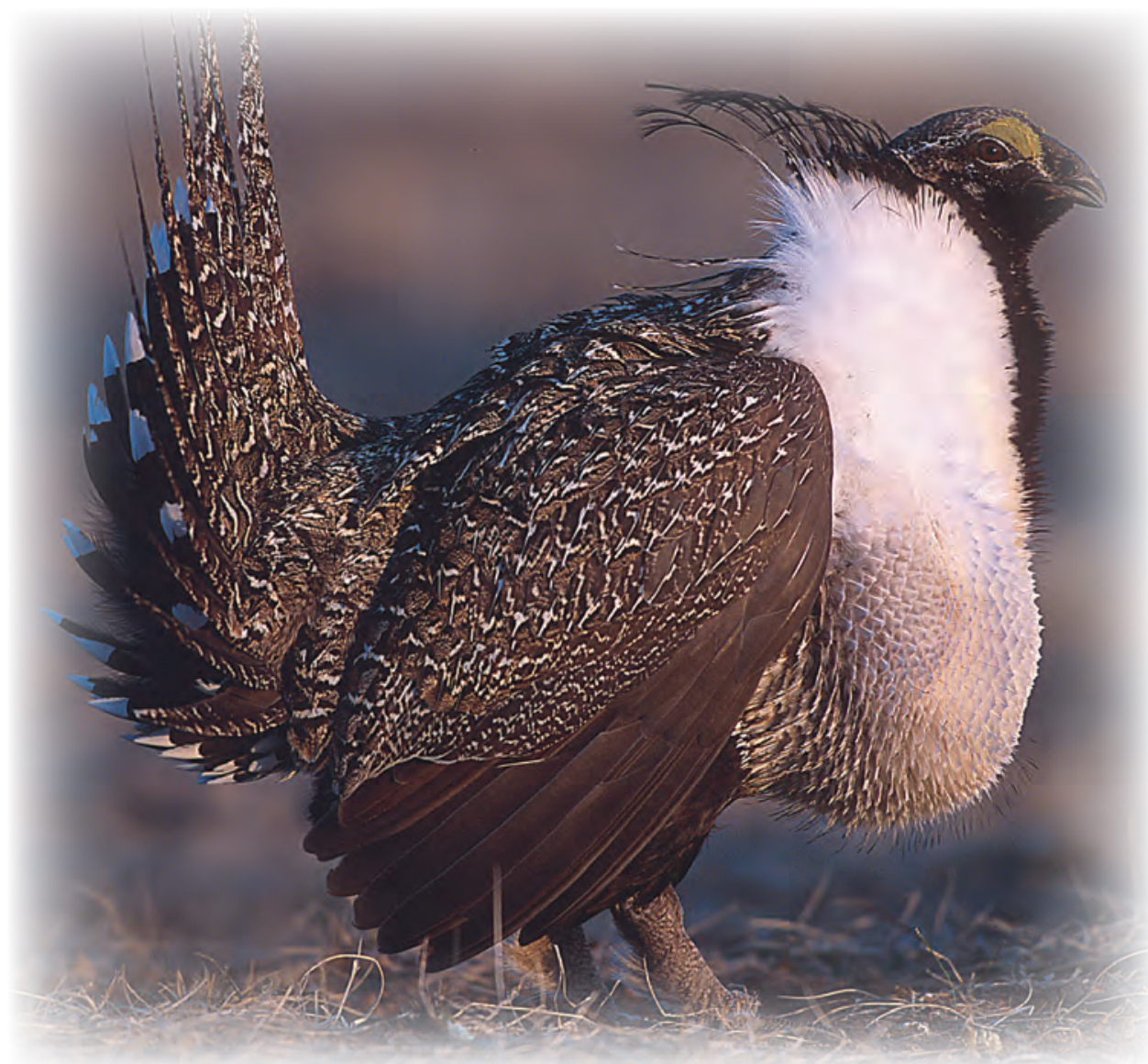

of domestic livestock, motorized recreation, urban expansion, hunting, and timber harvest, among others. These uses can affect the structure, composition, and function of Great Basin ecosystems, often resulting in altered hydrologic regimes, spread of exotic species, uncharacteristic wildfires, and degraded soils. Adaptive management of areas that encompass entire watersheds is needed to address these changing conditions, and such adaptive management requires reliable scientific information.

USGS scientists and collaborators have developed a long-term research strategy designed to address current and future research

Figure 1. The Great Basin

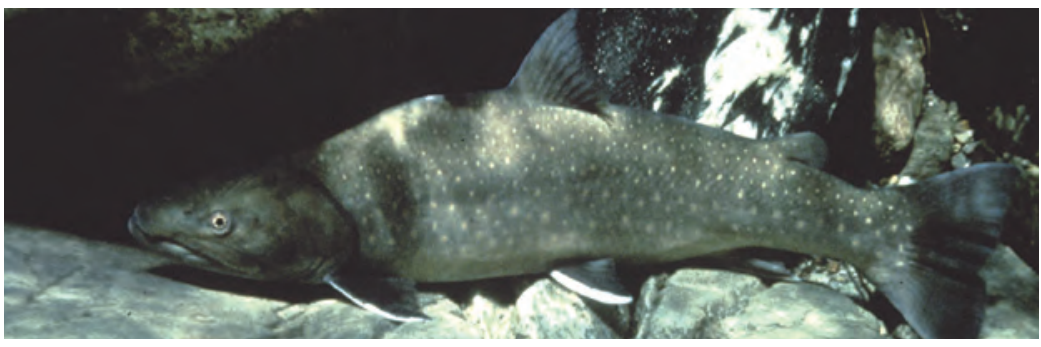

(4) Printed on recycled paper

needs for management of the Intermountain West's semi-arid ecosystems administered by the Department of the Interior. The research questions are relevant to four major western basins -the Interior Columbia, Snake River, Klamath, and Great basins. In addition to synthesizing highest-priority stated information needs of natural-resource managers into a few integrated research questions, the strategy draws from recent scientific literature to create applied research questions that support the strategy's ultimate goals. Also, the strategy recognizes the dynamic and unpredictable nature of ecosystems, and explicitly allows for a range of outcomes rather than an unvarying endpoint. 


\section{Guiding Principles}

- Transition from single-species to habitat- or guild-based management

- Recognition of disturbance regimes and events as triggers to system change

- Testing the existence of thresholds, alternative states, multiple pathways, and trends

- Treatment of management actions as opportunities for experimentation

- Testing of assumptions (e.g., indicators, causeeffect relationships), so that management can adapt to new information

- Implementation of monitoring and analysis at scales ranging from watersheds to management units to regions

- Use of control sites to separate natural variability from change induced by management

\section{Research Themes}

Five research themes were chosen jointly by managers and scientists from cooperating agencies across the Great Basin. Sample issues for each theme include:

\section{Rangeland health \\ - invasive plants \\ - biological diversity \\ - fire as a disturbance process \\ - soil chemistry \\ - biological soil crusts}

Landscape restoration

- habitat fragmentation and edge effects

- wildlife habitat

- invasive species

- soils

\section{Aquatic-terrestrial interface}

- riparian, wetland, and upland communities

- multiple-scale perspective

- springs

\section{Monitoring for adaptive management \\ - vegetation \\ - wildlife \\ - fishes \\ - soils}

- sagebrush-steppe habitats and sagebrush-

- expansion of junipers and pinyon pines

- salmonids

- threatened, endangered, and rare species

- ephemeral wetlands

\section{Species and habitats at risk} obligate species

- endemic fishess

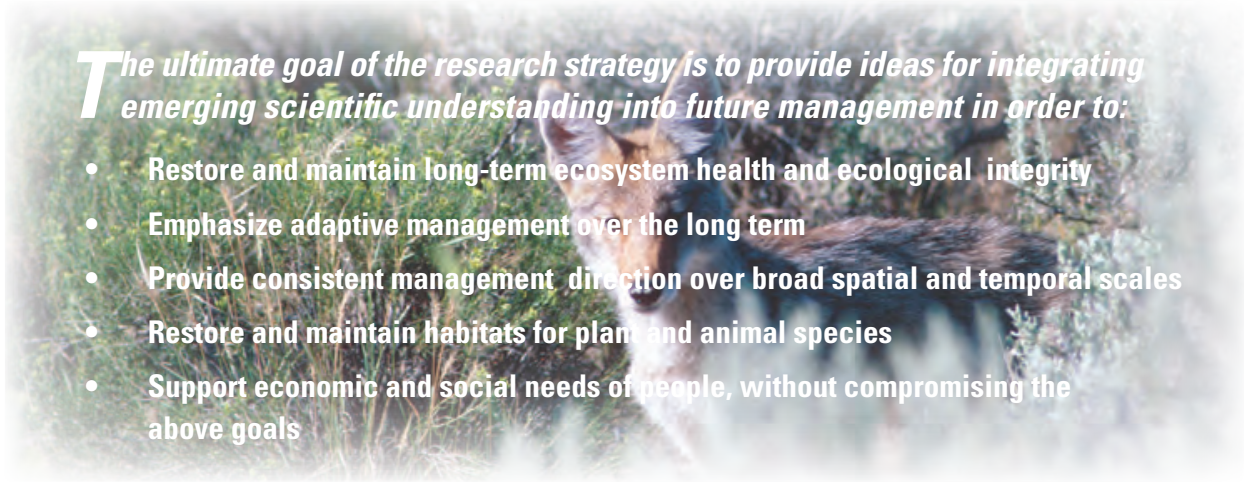

\section{Guiding Principles}

Seven principles guide the proposed research, and the research is organized in five themes. The strategy melds the use of observational studies with experimental manipulation, treating management actions as experiments whenever feasible. For each research issue, the strategy provides a broad framework of questions within which specific questions and hypotheses can be designed. Information justifying the importance of and need for research also accompanies each issue. Research questions in the strategy possess designations to guide prioritization of implementation. Designations reflect the magnitude and immediacy of the research need, as well as the relative risk associated with not undertaking the research.

\section{Examples of Research Questions}

Aquatic-Terrestrial Interface Theme: What are the composition, abundance, and trend of spring-dwelling biotas? How do soils and nearby communities (e.g., invertebrates, plants, large mammals, birds, granivorous mammals) respond to changes in spring management?

Landscape Restoration Theme: Within sagebrush ecosystems, how do soil characteristics, nutrient and water flows, vertebrate and invertebrate assemblages, and sagebrush-obligate species vary across the landscape in areas of different patch size, habitat quality (i.e., composition and cover of exotic forbs, native grasses, native forbs), grazing history, current grazing system, and distance from sagebrush "mainland"? In a mosaic of varying land uses and vegetation types, how does rate of habitat change and conversion compare with historic rates of change and conversion? Do size and geometry
Map of Great Basin produced by Robert G. Elston, Jr. MS, Biological Resources Research Center. Basin boundary follows Brussard et al. 1998. Great Basin-Mojave Desert Region in M.J. Mac et al. Status and Trends of the Nation's Biological Resources. 2 vols. U.S. Department of Interior, U.S. Geological Survey, Reston, Virg. Image credits: Sage-grouse, @Terry Steele; bull trout, Russ Thurow, Rocky Mountain Research Station; others public domain. Authors: Erik Beever and David Pyke. Designed by Sandra Arbogast

\section{The plan is available on the web at: http://fresc.usgs.gov/res_strat.pdf}

of fragments and their interspersion across the landscape predict the spread of exotics, nutrient flow into and from ecosystem fragments, or abundance of species with large or specialized habitat requirements?

Rangeland Health Theme: Are there plant or animal species that a) represent a particular use, ecosystem, or management concern; b) exert disproportionate effects on ecosystem composition and function; or c) are important functional components of more than one food web, plant-animal association, or ecosystem (i.e., link species)? If such species do exist, what factors limit the ability of trends in one species to predict dynamics of other species?

\section{Collaborators}

Management agencies and other cooperators were involved in the development of the strategy from beginning to end. Several groups collectively agreed on the five goals and research themes, and each management agency contributed their list of research needs. Their research questions were reviewed, sorted, combined, and edited based on current knowledge and methods of applied scientists. This filtering occurred through personal contacts with scientists and managers in meetings and workshops and through reviews of current scientific literature. As the strategy neared completion, cooperators again conducted a final review. Key cooperators in development of the plan included Oregon State University, Eastern Oregon Agricultural Research Station, The Nature Conservancy, USDI-Bureau of Land Management, USDIFish and Wildlife Service, USDI-National Park Service, USDI-Bureau of Reclamation, USDAAgricultural Research Service, and USDAForest Service.

For additional information contact:

USGS Information and Outreach

Forest \& Rangeland Ecosystem

Science Center

777 NW 9th St., Suite 400

Corvallis, OR 97330

541-750-1030 